\title{
Risk factors for acute myocardial infarction in women: evidence from the Royal College of General Practitioners' oral contraception study
}

\author{
Peter Croft, Philip C Hannaford
}

\begin{abstract}
To determine the pattern of risk factors for acute myocardial infarction associated solely with women a nested case-control study was carried out on cohort data collected during the Royal College of General Practitioners' oral contraception study. Smoking (adjusted relative risk 1.7 for light smokers and $\mathbf{4 . 3}$ for heavy smokers), hypertension (2.4), toxaemia of pregnancy $(2 \cdot 8)$, and diabetes mellitus $(6.9)$ were associated with a significantly increased risk of myocardial infarction. There was no significant trend of risk with social class. Current use of the pill increased the risk only among women who also smoked (relative risk 20.8 for heavy smokers). Previous use of the pill did not influence the risk of myocardial infarction. If heavy smokers also had a history of toxaemia of pregnancy their risk of myocardial infarction was further increased (relative risk 41.0). Other variables associated solely with women, such as parity, hysterectomy, and hormone replacement therapy, had little effect on the risk of having a myocardial infarction.

Overall, smoking was the most important independent risk factor and had a strong influence on risks associated with other factors.
\end{abstract}

\section{Introduction}

In the Western world one third of all the deaths that occur in women aged between 25 and 64 are caused by cardiovascular disease. The risk factors associated with ischaemic heart disease in women, however, are less well characterised than those that influence coronary artery disease in men. Previous studies have tended to confirm smoking, hypertension, clotting variables, and serum lipid concentrations as major risk factors in both men and women.' Less clear is the pattern of risk for characteristics associated solely with women. These include parity, toxaemia of pregnancy, hysterectomy, the menopause, hormone replacement therapy, and use of oral contraceptives. Study of these factors may help to explain both the mechanisms of risk of ischaemic heart disease among women and the reason for the difference in incidence between men and women.

The Royal College of General Practitioners' oral contraception study, though primarily designed to investigate the health effects of oral contraceptives, provided a valuable opportunity to examine other influences on myocardial infarction in women. A nested case-control study carried out on the cohort data allowed us to examine more variables than can usually be accommodated in longitudinal analysis.

\section{Subjects and methods}

Full details of the design of the study have been given elsewhere. ${ }^{2}$ In summary, during 14 months from
May 1968, 23000 women who had used oral contraceptives and a similar number of women who had never used them were recruited by 1400 general practitioners. Comprehensive information on use of the pill, all newly presenting episodes of morbidity, and causes of death were reported by the general practitioners at six monthly intervals after recruitment. Observation of the study cohort continues.

The rationale and theory of a case-control analysis of cohort data were outlined by Lubin. ${ }^{3}$ Essentially, controls matched for each case should represent subjects in the cohort known to be at risk of a first event at the time of the case event. All cases and controls came from the study cohort. The cases comprised all women who had had their first acute myocardial infarction (International Classification of Diseases (ICD), eighth revision, code 4I00-4109) while under observation in the study. The diagnosis was that reported by the general practitioner to the study; no specific criteria for diagnosis were given. In the case of a fatal first event the doctor's report was supplemented by information from the death certificate. Women in whom myocardial infarction was diagnosed before recruitment were excluded. The data were extracted in October 1987.

Three controls, who were matched for age with each case (index subject), were selected as follows. Three doctors who were still participating in the study were identified by random selection. Details of their recruited subjects were examined to find those who fulfilled the selection criteria-namely, date of birth within two years of the index subject's date of birth, no history of a myocardial infarction and still under observation when infarction was diagnosed in the index subject, and a different recruiting doctor from that of the index subject. One control was randomly selected per doctor. If there were no potential controls another doctor was randomly identified. The records of all selected subjects were examined and their relevant personal characteristics, details of their use of the pill, and previous medical history were extracted and categorised. Within each matched set all characteristics were those that pertained at the date of the index subject's myocardial infarction.

According to the Registrar General's classification, the women were grouped into four categories of social class ( 1 and 2, 3 non-manual, 3 manual, 4 and 5). Other factors examined in the analysis were parity, smoking, use of the pill, history of hypertension (ICD 4010), history of toxaemia of pregnancy (ICD 6370, 6371, 6379), diabetes mellitus (ICD 250, 7895), psychiatric history-psychosis (ICD 290-299), non-psychotic mental disorders (ICD 300-309), deliberate self harm (appropriate ICD E and $\mathrm{N}$ codes)-hysterectomy (ICD R690-694, R696), and use of hormone replacement therapy. The interaction of age with each of these factors was examined.

Full information was not available for 12 women: 
history of smoking was unknown in five, parity in three, and social class in four. If the missing data related to a control the value for the matched index subject was substituted. In theory this would tend to underestimate the relative risks associated with these factors. In practice, when these controls were omitted entirely any changes in the value of the relative risks were small. When data were missing for an index subject the whole matched set was removed from the analyses: five sets were thus removed.

\section{POWER AND STATISTICAL ANALYSIS}

There were 158 matched sets available for analysis, which was carried out with the PECAN program for conditional logistic regression analysis of matched case-control data. ${ }^{3}$ Each variable was first examined separately, and unadjusted relative risks were calculated. These were then adjusted for social class, smoking, and history of use of the pill. Further adjustments were made for other potential confounding variables, and confidence intervals were calculated. ${ }^{+}$

For 160 cases a ratio of three controls for each case gave a power of more than $90 \%$ to detect an increased relative risk of 2.5 or more with an exposure prevalence of $10 \%$ among the controls, or an increased relative risk of 3.0 or more with an exposure prevalence of $5 \%$ $\left(\alpha=0.05\right.$ one sided). ${ }^{5}$ Combinations of risk factors that seemed clinically relevant were examined and 95\% confidence intervals for the associated relative risks calculated. The size of the study was unlikely to have

TABLE II - Relative risk of acute myocardial infarction associated with characteristics of women in study

\begin{tabular}{|c|c|c|c|c|c|}
\hline & $\begin{array}{l}\text { No of } \\
\text { cases }\end{array}$ & $\begin{array}{c}\text { No of } \\
\text { controls }\end{array}$ & $\begin{array}{l}\text { Unadjusted } \\
\text { relative } \\
\text { risk }\end{array}$ & $\begin{array}{l}\text { Adjusted } \\
\text { relative } \\
\text { risk }\end{array}$ & $\begin{array}{l}95 \% \text { Confidence } \\
\text { interval for } \\
\text { adjusted relative } \\
\text { risk }\end{array}$ \\
\hline \multicolumn{6}{|c|}{ Use of oral contraceptives } \\
\hline Nevert & 64 & 227 & 1.0 & 1.0 & \\
\hline Previously & 67 & 186 & $1 \cdot 3$ & $1 \cdot 0$ & 0.7 to 1.6 \\
\hline Currently & 27 & 61 & 1.8 & 1.8 & 0.9 to 3.6 \\
\hline \multicolumn{6}{|c|}{ Smoking habit at recruitment } \\
\hline Non-smoker $\ddagger$ & 47 & $256^{\circ}$ & $1 \cdot 0$ & $1 \cdot 0$ & \\
\hline$<15$ Cigarettes a day & 42 & 126 & 1.8 & $1 \cdot 7$ & $1 \cdot 1$ to $2 \cdot 7$ \\
\hline$\geqslant 15$ Cigarettes a day & 69 & 92 & $4 \cdot 3$ & $4 \cdot 3$ & 2.6 to 6.9 \\
\hline \multicolumn{6}{|c|}{ Social class at recruitment } \\
\hline 1 and $2 \ddagger$ & 39 & 163 & $1 \cdot 0$ & 1.0 & \\
\hline 3 (Non-manual) & 18 & 38 & $2 \cdot 4$ & $2 \cdot 1$ & 1.0 to 4.6 \\
\hline 3 (Manual) & 74 & 184 & $2 \cdot 1$ & 1.7 & 0.9 to 2.9 \\
\hline 4 and 5 & 27 & 89 & $1 \cdot 6$ & $1 \cdot 2$ & $0 \cdot 6$ to $2 \cdot 4$ \\
\hline \multicolumn{6}{|c|}{ Parity at time of event } \\
\hline Nulliparousł & 7 & 25 & 1.0 & 1.0 & \\
\hline Para 1 & 22 & 63 & $1 \cdot 2$ & $0 \cdot 7$ & $0 \cdot 2$ to $2 \cdot 1$ \\
\hline Para 2 & 51 & 173 & 1.0 & $0 \cdot 6$ & 0.2 to 1.6 \\
\hline Para 3 & 41 & 115 & $1 \cdot 3$ & $0 \cdot 7$ & $0 \cdot 3$ to $2 \cdot 0$ \\
\hline Para 4 & 19 & 63 & $1 \cdot 1$ & $0 \cdot 7$ & 0.2 to 1.9 \\
\hline Para $5+$ & 18 & 35 & $1 \cdot 8$ & $0 \cdot 9$ & $0 \cdot 3$ to $2 \cdot 6$ \\
\hline
\end{tabular}

*Relative risk adjusted for social class, smoking, and use of oral contraceptives, except where an adjusting variable was itself being examined.

tReference subgroup.

TABLE III - Relative risk of acute myocardial infarction associated with relevant medical history

\begin{tabular}{|c|c|c|c|c|c|}
\hline & $\begin{array}{l}\text { No of } \\
\text { cases }\end{array}$ & $\begin{array}{c}\text { No of } \\
\text { controls }\end{array}$ & $\begin{array}{l}\text { Unadjusted } \\
\text { relative } \\
\text { risk }\end{array}$ & $\begin{array}{l}\text { Adjusted } \\
\text { relative } \\
\text { risk }\end{array}$ & $\begin{array}{l}95 \% \text { Confidence } \\
\text { interval for } \\
\text { adjusted relative } \\
\text { risk }\end{array}$ \\
\hline \multicolumn{6}{|l|}{ Toxaemia of } \\
\hline Hypertension & 44 & 49 & $3 \cdot 0$ & $2 \cdot 4$ & $1 \cdot 4$ to $4 \cdot 1$ \\
\hline \multicolumn{6}{|l|}{ Psychiatric history: } \\
\hline $\begin{array}{l}\text { Nonet } \\
\text { History without }\end{array}$ & 57 & 216 & $1 \cdot 0$ & $1 \cdot 0$ & \\
\hline $\begin{array}{l}\text { psychosis } \\
\text { History with }\end{array}$ & 90 & 236 & $1 \cdot 5$ & $1 \cdot 4$ & 0.9 to $2 \cdot 2$ \\
\hline psychosis & 11 & 22 & $2 \cdot 0$ & $2 \cdot 0$ & 0.8 to 4.9 \\
\hline Diabetes mellitus & 6 & 2 & $9 \cdot 0$ & $6 \cdot 9$ & $1 \cdot 1$ to 43.8 \\
\hline Hysterectomy & 13 & 50 & $0 \cdot 8$ & $0 \cdot 8$ & $0 \cdot 4$ to $1 \cdot 6$ \\
\hline $\begin{array}{l}\text { Hormone } \\
\text { replacement } \\
\text { therapy }\end{array}$ & 9 & 32 & $0 \cdot 8$ & $0 \cdot 8$ & 0.3 to 1.8 \\
\hline
\end{tabular}

*Relative risk adjusted for social class, smoking, use of oral contraceptives, history of toxaemia of pregnancy, and hypertension, except where an adjusting variable was itself being examined; hysterectomy and hormone replacement therapy also adjusted for each other.

†Reference subgroup.
TABLE IV-Interaction of smoking with use of oral contraceptives and history of hypertension and toxaemia of pregnancy. Figures are ratios of cases to controls with relative risk ( $95 \%$ confidence interval)

\begin{tabular}{|c|c|c|c|}
\hline & \multicolumn{3}{|c|}{ Smoking } \\
\hline & Never & $\begin{array}{c}<15 \text { Cigarettes } \\
\text { a day }\end{array}$ & $\begin{array}{l}\geqslant 15 \text { Cigarettes } \\
\text { a day }\end{array}$ \\
\hline \multicolumn{4}{|c|}{ Use of oral contraceptives } \\
\hline Never & $23: 135$ & $21: 54$ & $20: 38$ \\
\hline & $1 \cdot 0$ & $2 \cdot 0(1.0$ to 3.9$)$ & $3.3(1.6$ to 6.7$)$ \\
\hline \multirow[t]{2}{*}{ Previously } & 19:91 & $12: 50$ & $36: 45$ \\
\hline & $1.1(0.6$ to 2.2$)$ & $1.3(0.6$ to $2 \cdot 8)$ & $4 \cdot 3(2 \cdot 3 \operatorname{ton} 8 \cdot 0)$ \\
\hline \multirow[t]{2}{*}{ Currently } & $5: 30$ & $9: 22$ & $13: 9$ \\
\hline & $0.9(0.3$ to $2 \cdot 7)$ & $3 \cdot 5(1 \cdot 3$ to $9 \cdot 5)$ & $20 \cdot 8(5 \cdot 2$ to $83 \cdot 1)$ \\
\hline \multirow{3}{*}{ No } & History o & hypertension & \\
\hline & $32: 227$ & $28: 109$ & $54: 81$ \\
\hline & $1 \cdot 0$ & $1.8(1.0$ to 3.1$)$ & $4.8(2.8$ to 8.1$)$ \\
\hline \multirow[t]{2}{*}{ Yes } & $15: 29$ & $14: 17$ & $15: 11$ \\
\hline & $3.7(1.8$ to 7.6$)$ & $5 \cdot 8(2.5$ to 13.5$)$ & $9.0(3.7$ to 21.7$)$ \\
\hline \multirow{3}{*}{ No } & History of tox & mia of pregnancy & \\
\hline & $33: 224$ & $34: 108$ & $52: 88$ \\
\hline & 1.0 & $2 \cdot 2(1 \cdot 3$ to $3 \cdot 7)$ & $4 \cdot 5(2 \cdot 7$ to $7 \cdot 6)$ \\
\hline \multirow[t]{2}{*}{ Yes } & $14 \cdot 32$ & $8: 18$ & $17: 4$ \\
\hline & $3.4(1.6$ to 7.2$)$ & $3 \cdot 3(1 \cdot 3$ to $8 \cdot 3)$ & $41 \cdot 0$ (11.2 to $149 \cdot 4$ \\
\hline
\end{tabular}

the power to detect interactions that deviated significantly from a simple multiplication of risk.

\section{Results}

Table I shows the age distribution of the women with myocardial infarction. Table II details the relative risk of having a myocardial infarction associated with the personal characteristics of the women. The numbers of women in each group are also given. Neither current nor previous use of the pill was associated with significant increased relative risks (adjusted relative risk 1.8 and 1.0 respectively). Women who smoked were at significantly greater risk of heart disease. Heavy smokers ( 15 or more cigarettes a day) had over four times the risk of non-smokers (adjusted relative risk 4.3) whereas light smokers (less than 15 cigarettes a day) had nearly twice the risk of non-smokers (adjusted relative risk 1.7). There was a significant linear trend of risk with smoking $\left(\chi^{2}=40 \cdot 7\right.$, $\mathrm{df}=1$ ), and the point estimates showed little departure from that trend $\left(\chi_{*}^{2}=0 \cdot 6, \mathrm{df}=2\right.$ for deviation from linearity). Parity was shown not to be a significant risk factor for myocardial infarction. There was no clear trend of changing risk with social class. Adjustment of crude estimates for potential confounding effects made little difference to the relative risks. The small changes in the relative risks associated with use of the pill, social class, and parity (table II) were due to the confounding effect of cigarette smoking.

A history of toxaemia of pregnancy, hypertension, or diabetes mellitus significantly increased a woman's risk of developing a myocardial infarction (table III). The relative risks for toxaemia of pregnancy and hypertension remained significantly raised after any confounding effects between the two diagnoses were removed (adjusted relative risk 2.8 and 2.4 respectively). This suggested that these variables are independent risk factors for myocardial infarction. A psychiatric history with or without the mention of a psychotic episode was not associated with a significantly increased risk (adjusted relative risk 2.0 and 1.4 respectively). Similarly a history of hysterectomy and use of hormone replacement therapy were not associated with raised relative risks. The relative risks of the variables studied did not change significantly with age.

Table IV describes the interaction between smoking and use of the pill, a history of hypertension, and a history of toxaemia of pregnancy. As already shown in table II, the relative risk of myocardial infarction increased the more a woman smoked. Acute myocardial infarction was commoner among women who smoked 15 or more cigarettes a day, regardless of their 
use of the pill. The estimates of relative risk, however, suggested that current use of the pill enhanced the risk of heavy smokers (relative risk $20 \cdot 8$ ). In addition, light smoking seemed to influence the risk of myocardial infarction only among women who were also currently taking the pill (relative risk $3 \cdot 5$ ). There was no association of myocardial infarction with current or previous use of the pill among non-smokers. There was little evidence of interaction between smoking and hypertension. The relative risk of myocardial infarction among heavy smokers seemed to be affected by a history of toxaemia of pregnancy $(41 \cdot 0)$ but had broad confidence intervals because of the small number of events.

Table $\mathrm{V}$ examined whether the relative risks associated with a history of hypertension or toxaemia of pregnancy were altered by use of the pill. There was little evidence for this as the relative risks for hypertension and toxaemia of pregnancy were similar in never, previous, and current users of the pill.

TABLE V--Interaction of use of oral contraceptives with history of hypertension and toxaemia of pregnancy. Figures are ratios of cases to controls with relative risks ( $95 \%$ confidence interval)

\begin{tabular}{|c|c|c|c|}
\hline & \multicolumn{3}{|c|}{ Use of oral contraceptives } \\
\hline & Never & Former use & Current use \\
\hline \multicolumn{4}{|c|}{ History of hypertension } \\
\hline \multirow{2}{*}{ No } & $46: 198$ & $51: 169$ & $22: 53$ \\
\hline & 1.0 & $1.5(0.9$ to 2.4$)$ & $2 \cdot 0(1.1$ to 3.9$)$ \\
\hline \multirow[t]{3}{*}{ Yes } & $18: 29$ & $16: 17$ & $5: 8$ \\
\hline & $5 \cdot 4(2 \cdot 6$ to $11 \cdot 2)$ & $2 \cdot 6(1.3$ to $5 \cdot 0)$ & $7 \cdot 7(1 \cdot 2$ to $49 \cdot 2)$ \\
\hline & History of tox & mia of pregnancy & \\
\hline \multirow{2}{*}{ No } & $43: 208$ & $47: 150$ & $24: 59$ \\
\hline & 1.0 & $1.3(0.8$ to 2.0$)$ & $2 \cdot 0(1 \cdot 0$ to $4 \cdot 0)$ \\
\hline \multirow[t]{2}{*}{ Yes } & $21: 19$ & $20: 36$ & $3: 2$ \\
\hline & $2.6(1.3$ to 4.9$)$ & $4.0(1.9$ to 8.8$)$ & $3.2(1.0$ to 10.9$)$ \\
\hline
\end{tabular}

\section{Discussion}

This study confirmed the importance of cigarette smoking, diabetes, and hypertension as risk factors for acute myocardial infarction in women. Current use of the pill was associated with an increase in risk only in women who were also smokers. The risk associated with a history of toxaemia of pregnancy was independent of that associated with hypertension. Relative risks for women who had had toxaemia of pregnancy were further increased if these women also smoked heavily.

\section{BIAS}

Recall bias did not apply to this study as all the history of exposure was collected before the investigated event. The diagnoses relating to each woman in the study were those given by her general practitioner. Inevitably the diagnostic criteria used for acute myocardial infarction vary, and the nature of the oral contraception study was such that no explicit criteria for any condition were imposed on the participating doctors. This would be important if doctors' knowledge of their patients' medical history was likely to influence the diagnosis of myocardial infarction - for instance, if a general practitioner made the diagnosis more commonly in women with a history of hypertension. If a sizable number of participating doctors followed a similar diagnostic pattern the estimated risks for that variable would be biased. In our dataset a similar proportion of cases were admitted to hospital at the time of their heart attack irrespective of their medical history. This indirect measure of the influence of medical history on the general practitioner's actions argues against any systematic bias.

Details of daily cigarette consumption had not been updated since the start of the study. Assuming that the women in the cohort reflected national trends of decreasing prevalence of smoking, ${ }^{6}$ our observations would underestimate the effect of smoking.

Approximately $63 \%$ of the recruited women were lost to follow up in the main cohort study. This was predominantly because patients left the area covered by their recruiting doctor. This should not have been a material source of bias as it was unlikely to be related to subsequent myocardial infarction and the risk factors of interest.

\section{COMPARISON WITH OTHER STUDIES}

Although smoking carries a relatively smaller cardiovascular risk in women than men, possibly because of different inhalation habits, ${ }^{7}$ it consistently contributes the greatest excess risk. ${ }^{8}$ Our estimates of the relative risk of smoking were consistent with those in other studies ${ }^{9.12}$ Higher risks among younger smokers have been reported elsewhere. ${ }^{10}{ }^{13}$ We were unable to confirm this, although there was a non significant doubling of risk in smokers aged under 50 compared with smokers aged 50 and over. The higher relative risks found in smokers currently using the pill have been reported by others. ${ }^{14} \mathrm{~A}$ finding not previously reported, however, is the enhanced risk estimate in women who smoke and have a history of toxaemia of pregnancy. There was no evidence in this study for a trend of increasing risk of myocardial infarction with parity. This is consistent with several other studies, ${ }^{91516}$ although evidence to the contrary comes from mortality data ${ }^{17}$ and some cohort studies. ${ }^{112}$

The association between hypertension and myocardial infarction in women has been found in other studies.' In contrast, Mann et al found an association between toxaemia of pregnancy and myocardial infarction but no separate effect for hypertension. ${ }^{9}$ Toxaemia of pregnancy and hypertension are related: hypertensive women may develop toxaemia, while a quarter of women who experience hypertension in pregnancy may develop established hypertension within 10 years. ${ }^{18}$ In our study there was some relation between the two diagnoses, but after adjusting each for the effects of the other they seemed to be independently associated with myocardial infarction. The physiological changes that occur during toxaemia of pregnancy may have long term cardiovascular effects. ${ }^{19}$ Alternatively, if hypertension was incompletely ascertained among the women in the study, including those who had had toxaemia, toxaemia could still have influenced coronary risk primarily because it caused established hypertension.

The influence of the menopause and postmenopausal oestrogen therapy on coronary risk is still controversial. ${ }^{2021}$ Evidence suggests that the risk is concentrated among women who have had an early natural or surgical menopause, and the only clear benefit of oestrogen replacement therapy is when it is prescribed for these high risk patients. Our findings were consistent with there being no increased risk associated with either hormone replacement therapy or having had a hysterectomy, but confidence intervals were wide.

In the few studies that have explored the social determinants of ischaemic heart disease in women no clear trend of risk associated with social class has emerged. Perhaps this is because the usual measure of social class relates to the partner's occupation. Reports on the effects of psychiatric illness are also sparse. Although our risk estimates were not significant, there was a trend of rising coronary risk across the minor and major categories of psychiatric illness. An increase in non-fatal myocardial infarction has been reported in women who have a history of mental illness. ${ }^{22}$ In the case-control study of Mann et al mental illness was considered to be secondary to other factors, ${ }^{9}$ and in 
the Gothenberg study the only association was with angina. ${ }^{23}$ Within our study 11 women had a history of psychotic illness before their heart attack. The interval between these two events ranged from 19 to 181 months with a mean of 107 months. Possible reasons for this association may include selection bias produced by certain characteristics of the patient, the long term effects of psychotropic treatment, and the less specific effect of "stress."

\section{IMPLICATIONS}

A recent report has shown that nearly $95 \%$ of sexually active women under the age of 30 may have used oral contraceptives at some time in their lives..$^{2+}$ We have confirmed that current use of the pill among smokers is associated with an increased risk of a myocardial infarction, and there is a clear need for women who are using the pill to be discouraged from smoking. The incidence of ischaemic heart disease in women accelerates after the menopause and then becomes an important cause of morbidity and mortality. If previous use of the pill carried even a small residual relative risk this may have a serious effect on the absolute number of women who have had a heart attack. This is particularly important now that so many women have taken the pill, and it is reassuring, therefore, to find that previous use is unlikely to carry a residual risk of myocardial infarction. A small increase in risk would still, however, be within the bounds of our estimate, and as there is other case-control evidence that women who have taken the pill for long periods may have some residual risk of myocardial infarction ${ }^{25}$ further study is needed.

Morbidity found to predispose a woman to a heart attack included hypertension, toxaemia of pregnancy, diabetes, and, possibly, psychiatric illness. With the exception of established diabetes all have a fairly high prevalence among women and so are potentially important in terms of prevention. From the doctor's viewpoint these diseases cannot be prevented, though their effects can be modified. Patients with a history of toxaemia should be informed that smoking greatly increases their chance of a heart attack. The overall incidence of myocardial infarction in women might be reduced if the prevalence of these illnesses was reduced.

We examined the estimated risks associated with factors specific to women. Of these factors, only toxaemia of pregnancy carried a definite risk. Although the sex difference in the incidence of coronary disease remains to be explained, the nature of the risks examined here is similar to that reported for men. ${ }^{26}$ In particular, smoking is an important independent risk factor for acute myocardial infarction and has a strong influence on the risks associated with other factors. The recent decline in the prevalence of smoking among women has been slower than that among men, and women tend to start smoking at a younger age and in greater quantity. ${ }^{67}$ Smoking among women remains a major public health concern.

We thank Dr Valerie Beral for her advice in planning the study; Ms Allison Douglas and Mr Martin Shipley for statistical help; the staff of the Manchester Research Unit for their patience in collating the data; and the 1400 general practitioners who contributed data to the main cohort study. The studv is supported by the Medical Research Council. The costs of pilot trials and current supplementary expenditure were met by the scientific foundation board of the Royal College of General Practitioners. The board thanks Organon Laboratories Ltd, Ortho Pharmaceutical Corporation, Schering Chemicals Ltd, G D Searle and Co Ltd, Syntex Pharmaceuticals Ltd, and John Wyeth and Brother Lid for financial support.

1 Johansson S, Vedin A, Wilhelmsson C. Myocardial infarction in women Epidemiol Rez' 1983:5:67-95.

2 Roval College of General Practitioners. Oral contraceptives and health. London Pitman Medical, 1974.

3 Lubin JH. Extensions of analytic methods for nested and population-based incident case-control studies. F Chronic Dis 1986;39:379-88.

+ Breslow NE, Day NE. Statistical methods in cancer research. Vol 1. The analvsis of case-control studies. Lyons: International Agency for Research on Cancer. 1980. (IARC Scientific Publication No 32 .)

5 Casagrande JT, Pike MC, Smith PG. An improved approximate formula for calculating sample sizes for comparing two binomial distributions. Biometrics 1978; 34:483-6.

6 Office of Population Censuses and Survers. General household survev, 1982. London: HMSO, 198

7 Doll R, Gray R, Hafner B, Peto R. Mortality in relation to smoking: 22 years observations on female British doctors. Br Med f 1980;280:967-71.

8 Willett WC, Green A. Stampfer MJ, et al. Relative and absolute excess risks of coronary heart disease among women who smoke cigarettes. $N$ Engl I Med 1987;317:1303-9

9 Mann JI, Doll R, Thorogood M, et al. Risk factors for myocardial infarction in young women. British Journal of Preventive and Social Medicine. 1976 30:94-100

10 Rosenberg L, Kaufman DW, Helmrich SP, Miller DR, Stolley PD, Shapiro S. Myocardial infarction and cigarette smoking in women younger than 50 years of age. F.A.MA 1985;253:2965-9.

11 Bengtsson C. Ischaemic heart disease in women. A study based on a randomised population sample of women and women with myocardia infarction in Göteborg, Sweden. Acta Med Scand [Suppl] 1973:549:1-128.

12 Mant D, Villard-Mackintosh and angina pectoris in young women. I Epidemiol Community Health 1987:41:215-9.

13 Slone D, Shapiro S, Rosenberg L, et al Relation of cigarette smoking to mrocardial infarction in voung women. $N$ Engl f Med 1978;298:1273-6.

14 Shapiro S, Slone D, Rosenberg L, Kaufman DW, Stolley PD, Miettinen OS Oral contraceptive use in relation to myocardial infarction. Lancet $1979 ; \mathrm{i}$ :

15 la Vecchia CV, Franceschi S, Decarli A, Pampallona S, Tognoni G. Risk factors for myocardial infarction in young women. Am $\mathcal{F}$ Epidemiol 1987 125:832-43.

16 Colditz GA, Willett WC, Stampfer MJ, Rosner B, Speizer FE, Hennekens $\mathrm{CH}$. A prospective study of age at menarche, parity, age at first birth and coronary heart disease in women. Am $\mathcal{F}$ Epidemiol 1987;126:861-70.

17 Beral V. Long-term effects of childbearing on health. $\mathcal{F}$ Epidemiol Community Health 1985;39:343-6.

18 Svensson A. Hypertension in pregnancy: long-term effects on blood pressure in mothers and children. Acta Med Scand [Suppl] 1985;695:1-50.

19 Moore MP, Redman CWG. Hypertension in pregnancy. In: Bonner J, ed. Recent advances in obstetrics and gynaecologv. Edinburgh: Churchill Living Recent advances in
stone, 1987:15.

20 Colditz GA, Willet WC, Stampfer MJ, Rosner B, Speizer FE, Henneken $\mathrm{CH}$. Menopause and the risk of coronary heart disease in women. $N$ Engl $\mathrm{f}$ Med 1987:316:1105-10.

21 Wilson PWF, Garrison RJ, Castell WP. Postmenopausal oestrogen use, cigarette smoking, and cardiovascular morbidity in women over 50: the Framingham study. N Englf Med 1985;313:1038-43.

22 Tennant CC. Stress and coronary heart disease. Aust $N Z \mathcal{F}$ Psychiatry 1987;21:276-82.

23 Hallstrom T, Lapidus L, Bengtsson C, Edstrom K. Psychosocial factors and risk of ischaemic heart disease and death in women: a twelve year follow-up of participants in the population study of women in Gothenberg. Sweden. 7 Psychosom Res 1986;30:451-9.

24 Royal College of General Practitioners' Manchester Research Unit. New oral contraception study: pilot trial report. 7 R Coll Gen Pract 1986;36:545-6.

25 Slone D, Shapiro S, Kaufman DW, Rosenberg L, Miettinen O, Stolley PD. Risk of myocardial infarction in relation to current and discontinued use of Risk of miocardial infarction in relation to curren
oral contraceptives. $N$ Eng $\mathcal{F}$ Med 1981;305:420-4.

26 McGill HC, Stern MP. Sex and atherosclerosis. In: Paoletti R, Gotto AM, eds. Atherosclerosis reviews. No 4. New York: Raven Press, 1979:157-242.

27 Fielding JE. Smoking and women. Tragedy of the majority. $N$ Engl f Med 1987:317:1343-5.

(Accepted 6 December 1988) 